\title{
AN AMERICAN PORCELAIN CONTAINING NO FREE SILICA.
}

By Arthur S. Watts.

The following is one of a series of studies conducted with the object of producing a practical porcelain body which is free from the faults due to the presence of free silica. The chief of these faults is supersensitiveness to sudden change of temperature. Second only to this fault is the tendency to excessive warping The mode of procedure in this study was as follows:

A standard porcelain body was separated into its two essentials: (a) plastics, including all clays, and (b) non-plastics, including all feldspar, whiting, and flint. The non-plastic portion was calcined at a temperature just sufficient to produce a pyrochemical action between the feldspar and whiting and to allow them to act on the flint. Such a calcine, however, must not reach the glossy stage as it would be too difficult to pulverize. The calcine or semi-fusion was chilled by plunging while hot into cold water and the friable. mass resulting was then pulverized in a ball mill. The pulverized calcine and the clays were then mixed in such proportions as to produce a porcelain having the same chemical composition as the normal porcelain with which it was compared. For this study the following bodies were prepared:

\begin{tabular}{|c|c|c|c|}
\hline & $\begin{array}{l}\text { Body I. } \\
\text { Per cent. }\end{array}$ & $\begin{array}{l}\text { Body } \\
\text { Per ce }\end{array}$ & \\
\hline Canadian feldspar......... & 20 & 20 & \\
\hline Whiting. . . . . . . . . . & 2 & 2 & Calcined at cone 3 \\
\hline Flint $\ldots \ldots \ldots \ldots \ldots$ & 33 & 33 & \\
\hline Tennessee ball clay No. $7 \ldots$. & Io & 10 & \\
\hline Florida kaolin . . . . . . . . . & 10 & IO & \\
\hline Edgar Georgia kaolin........ & 25 & 25 & \\
\hline
\end{tabular}

The calcine vitrified to a dense, opaque mass at cone 3 . A microscopic study disclosed, however, that all of the flint had not dissolved but that about io to 12 per cent free flint remained. The calcine, after removal from the kiln, was reheated and plunged 
into cold water, resulting in the shattering of the mass into small fragments which were ground in about 5 hours into a powder which passed a 200-mesh sieve with 2 per cent residue.

The two bodies, I and J, were made up and fired to cones 7 and ro.

At cone 7 , Body I developed a cream color and an absorption of 4.4 per cent, while Body J developed a good white color and had a vitreous structure, the absorption being 2.12 per cent. At cone ro, Body I developed a pale-cream color and an absorption of 0.7 per cent, while Body $\mathrm{J}$ was blue-white in color and nonabsorbent. The color and absorption were thus greatly improved by the calcination of the non-plastics.

The two bodies were then tested for resistance to sudden temperature changes with the following results: Body $J$, even though of denser structure, possessed approximately three times the resistance to sudden temperature change displayed by Body I-prepared exclusively from raw materials.

\section{Conclusions.}

By calcining or semi-fusing the fluxes and flint prior to incorporation in a porcelain body, the maturing point can be lowered approximately two cones, the color vastly improved, and the resistance to sudden temperature changes improved approximately 200 per cent.

The objection to such a method of manufacture is the extra cost of preparing such a calcine. To offset this we have the saving in kiln maintenance and the fuel saving from the lowering of the maturing temperature of the bisque fire. The degree of pulverization necessary in the feldspar used could doubtless be reduced somewhat which would also mean some saving.

Another possibility which is apparent from this study is the reduction in the amount of flux required in case a lowering of the firing temperature is not desired.

Departmant of Ceramic Emginghering, Oho State UNTVhretty,

Columeus, Orro. 